\title{
CONSUMPTION OF PHOSPHORUS AND PRODUCTION OF ALKALINE PHOSPHATASE DUR- ING GROWTH OF Streptomyces coelicolor IN A RICH MEDIUM
}

\section{ISMINI NAKOUTI AND GLYN HOBBS}

School of Pharmacy and Biomolecular Sciences, Liverpool John Moores University, Byrom Street, Liverpool, L3 3AF, UK.

${ }^{*}$ Corresponding Author: Email- g.hobbs@livjm.ac.uk

Received: January 26, 2012; Accepted: February 22, 2012

\begin{abstract}
The growth of Strteptomyces coelicolor in a complex medium containing yeast extract, malt extract and glucose exhibited a biphasic mode of biomass accumulation. The first phase was associated with rapid biomass formation, phosphorus utilisation and lack of pigment production. The second stage was marked by slower growth and pigment formation. The demarcation between these phases appeared to result from the depletion of phosphorus in the media, which in turn allowed the red prodigiosin-like pigment to be expressed. Biomass formation appeared to involve the accumulation of phosphorus in the cells reaching a maximum level of $3.7 \%$ of the dry weight. The depletion of phosphorus provoked the increase in alkaline phosphatase activity, which in turn produced a transient release of phosphorus into the medium, presumably from stored cellular phosphorus. Although glucose was consumed during growth, it did not constitute the only carbon source as the appearance of significant amounts of ammonium ions in the broth indicated deamination of amino compounds.
\end{abstract}

Key words- Alkaline phosphatase, ammonium production, fermentation, phosphorus, Streptomyces coelicolor.

Citation: Ismini Nakouti and Glyn Hobbs (2012) Consumption of Phosphorus and Production of Alkaline Phosphatase during Growth of Streptomyces coelicolor in a Rich Medium. International Journal of Microbiology Research, ISSN: 0975-5276 (Print) \& E-ISSN:0975-9174, Volume 4, Issue 1, 2012, pp.-164-167.

Copyright: Copyright(02012 Ismini Nakouti and Glyn Hobbs. This is an open-access article distributed under the terms of the Creative Commons Attribution License, which permits unrestricted use, distribution, and reproduction in any medium, provided the original author and source are credited.

\section{Introduction}

Phosphate (organic and inorganic) is a fundamental component of microorganisms and underpins the energy currency within a cell. It can be found in the form of pyrophosphate, orthophosphate, polyphosphate, phosphorylated sugars, nucleotides or other phosphorylated moieties [17]. Phosphate is often a growth-limiting element especially for soil bacteria due to the fact that phosphate exists naturally in the form of insoluble salts [16].

Many bacteria acquire phosphate by releasing alkaline phosphatases, enzymes that generate free phosphate normally under conditions of phosphate starvation [16, 17].

Streptomycetes are a group of high $\mathrm{G}+\mathrm{C}$ Gram-positive soil bacteria. They are aerobic, mycelia-forming organisms that undergo complex morphological differentiation, which includes the sequential production of substrate mycelium, aerial mycelium, and spores. Nutritionally, the streptomycetes are extremely versatile. A wide variety of carbon sources can be utilized, such as sugars, amino acids, alcohols and some aromatic compounds [10-11].
These bacteria are general saprophytes, which mean that they gain nourishment directly from dead or decaying organic matter. They secrete extracellular enzymes and adsorb the soluble breakdown products of the interaction of these enzymes with insoluble polymers, such as polyssacharides and starch. Streptomycetes grow in carbohydrate replete environments where nitrogen and phosphorous are in poor supply [10]. They produce secondary metabolites, including $60 \%$ of the 10-12,000 antibiotics known today [2]. They have also been shown to produce alkaline phosphatases under phosphate limitation in order to capture phosphate and compete in their environment [17].

Production of secondary metabolites and phosphate regulation are intimately linked [8-9]. Streptomyces griseus IMRU 3570 (S. griseus) was found to release a significant level of alkaline phosphatases, which coincide with candicidin and tetracycline biosynthesis under phosphate deprivation [13-17]. Under phosphate replete conditions the transcription of the antibiotic biosynthetic genes is repressed [15]. Furthermore in Streptomyces coelicolor 
(S. coelicolor) the synthesis of actinorhodin and undecylprodigiosin is negatively regulated by high concentrations of phosphate $[5,9]$. In S. coelicolor and S. lividans antibiotic production is controlled by the PhoR-PhoP system, which regulates the alkaline phosphatase gene, phoA [16-21]. In S. lividans mutants lacking PhoR or PhoR and PhoP are deficient in the ability to produce alkaline phosphatases and are capable of overproducing actinorhodin and undecylprodigiosin in the presence of high phosphate concentrations [20].

Physiological studies using $S$. coelicolor require a reproducible, robust and characterised growth environment. This organism aggregates and forms pellets in the majority of submerged culture conditions making such studies difficult. Growth in media containing yeast extract and malt extract assists in achieving rapid and dispersed growth, which is generally reproducible [14]. While this organism appears to flourish in complex nutrient sources, the relationship between $S$. coelicolor and these components is not well understood. To develop an understanding of the interaction of this organism with its complex nutrients, we have tended to try to make this strain grow on chemically defined media, which bare little resemblance either to nature or an industrial production setting. We have set out to investigate the growth of $S$. coelicolor on a complex medium where a major determinant of the organism's responses is phosphate.

\section{Methods}

Microorganism and culture conditions: S. coelicolor A3 (2) was used throughout. The culture was maintained on Mannitol Soya Agar [7]. Bioreactors (Applikon, 1.8 L working volume) were inoculated to give a final spore concentration of $1 \times 106 \mathrm{spores} / \mathrm{ml}$. The broth used in this study was a modified form of yeast extract/ malt extract (YEME) medium containing $4 \mathrm{~g}$ yeast extract (Oxoid), $10 \mathrm{~g}$ malt extract (Sigma) and $4 \mathrm{~g} \mathrm{D}$ - (+)-glucose (Sigma) [14]. The bioprocess was controlled at $700 \mathrm{rpm}, 300 \mathrm{C}$ and $1.0 \mathrm{v} / \mathrm{v}$ per min aeration. The fermenter was linked to an MX3 autosampler (New Brunswick Scientific) and samples were taken at times specified on the figures.

\section{Assays}

Inorganic phosphorus was measured according to Plummer, 1987. Alkaline phosphatase was assayed according to Moura et al., 2001 [17]. Glucose was measured by using a glucose oxidase assay kit (Boehringer Mannheim). Biomass accretion was estimated by measurement of dry weight. Protein measurement has been conducted using the Bradford assay (Biorad).

\section{Result And Discussion}

S. coelicolor A3 (2) was grown in a modified version of YEME broth. This differed from the more usual formulation in that sucrose, glycine and magnesium chloride were omitted. Preliminary experiments had been conducted to establish the effect of storage in the autosampler on biomass, residual nutrient concentrations and enzyme activity. The results indicated that these parameters remained almost constant for the period of storage.

\section{Consumption of phosphorus and biomass accumulation in small scale fermentation:}

Biomass formation is shown in Figure $1 \mathrm{~A}$. Following a lag phase of approximately 10 hours during which germination of the spores occurred biomass levels increased rapidly over the period 10-16 hours. Growth at this point then slowed, culture morphology became pelleted and a second biomass accumulation phase was evident (16-24 hours). This coincided with red pigment production in the fermenter, indicative of undecylprodigiosin biosynthesis.

Previous studies had demonstrated the importance of phosphorus depletion in the control of pigment production in this organism [8]. Shake flask experiments defined the growth-limiting nutrient in this medium formulation and had identified phosphorus as the most likely limiting element. Examination of residual phosphorus levels in the fermentation broth (Figure 1 B) revealed a biphasic pattern of depletion that mirrored biomass accumulation. The ratio of phosphorus per unit biomass produced was calculated. On examination this revealed that cells accumulated phosphorus up to a maximum of $3.7 \%$ of the biomass on a dry weight basis (12 hours post inoculation), after which the ratio of phosphorus to biomass declined rapidly. This stabilisation coincided with the second phase of biomass accretion, which was occurring at a slower rate than the first phase. This change in cell-associated phosphorus could reflect a number of physiological events. Firstly it may simply be due to the increased demand for phosphate associated with increased levels of RNA in rapidly growing cells [4]. Secondly it may reveal that this organism accumulates phosphorus in some stable form, possibly in teichoic acids, which may at a later stage be metabolised to release phosphate under starvation conditions, a phenomenon previously described in Bacillus [6-19].

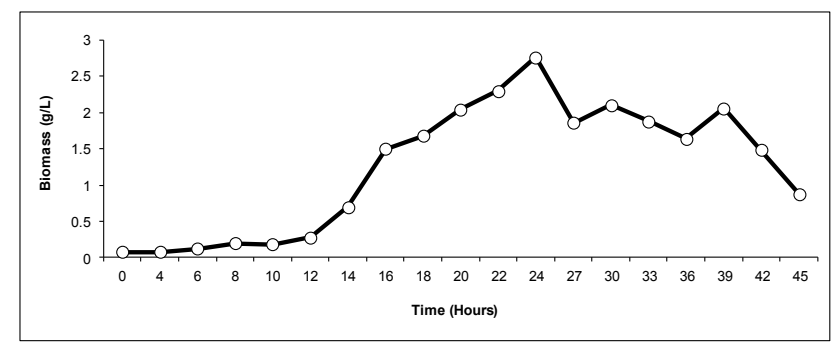

Fig. 1A- Fermentation profile of Streptomyces coelicolor growing in modified YEME media. Biomass accumulation, g/L dry weight . (O).

Alkaline phosphatase production and phosphorus depletion: Phosphorus is continuously cycled during the growth of microorganisms from inorganic phosphate to organic phosphate forms, such as ATP, nucleic acids, phospholipids, wall polymers, polyphosphates and other organic phosphate containing molecules. Central to these cycles is enzymatic release of the phosphate groups. One key enzyme involved in this catalysis in bacteria is the extracellular alkaline phosphatases. Extracellular alkaline phosphatase activity was detected during the spore germination phase and transiently declined thereafter (Figure $1 \mathrm{~B}$ ). As residual free phosphorus levels declined over the rapid biomass accumulation phase, alkaline phosphatase activity rose sharply reaching a maximum at 22 hours. Coincident with this peak in activity we measured an elevation in residual free inorganic phosphorus. Since no addition of phosphorus had been made to the culture, this indicated that enzymes had released phosphorus from the biomass. Interestingly this appearance of extracellular phosphorus was not associated with cell lysis (as indicated by the increasing 
biomass levels). It is therefore possible that cell bound phosphorus; possibly from teichoic acids known to be present in Streptomycetes [1] was released into the medium. This mechanism has previously been characterised in $B$. substilis [3-6].

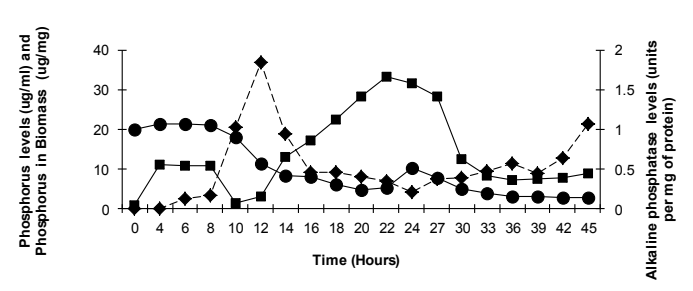

Fig. 1B- Fermentation profile of Streptomyces coelicolor growing in modified YEME media. Soluble phosphorus levels, $\mathrm{mg} / \mathrm{ml}(\mathbf{O})$, phosphorus in biomass, $\mathrm{mg} / \mathrm{mg}(\bullet)$ and alkaline phosphatase activity (-)

\section{Nutrient utilisation}

Given the complex medium we investigated the consumption of carbon sources from the broth to establish whether glucose was being used as a primary energy source. The amount of glucose consumed by the organism was maximally $2.2 \mathrm{~g} / \mathrm{L}$, yet biomass levels reached $2.8 \mathrm{~g} / \mathrm{L}$, suggesting that glucose was not the only carbon source being utilised (Figure $1 \mathrm{C}$ ). Ammonium levels exhibited a steady increase with time throughout growth, indicating that probably amino acids and peptides were being deaminated and the carbon backbones used in central metabolism. This is consistent with previous studies on Actinomycetes, where amino acids often function as the primary carbon source even when simple sugars are present [12].

The release of ammonium ions may well explain why the blue actinorhodin pigment was not detected through out the fermentation. Actinorhodin production has been shown to be repressed in the presence of ammonium ions [5-8] and as little as $1 \mathrm{mM} \mathrm{NH} 4+$ is known to prevent actinorhodin expression. Undecylprodigiosin is less sensitive to repression by ammonium ions; levels higher than $50 \mathrm{mM} \mathrm{NH} 4+$ are necessary to inhibit its formation, which might explain the appearance of this pigment during the fermentation.

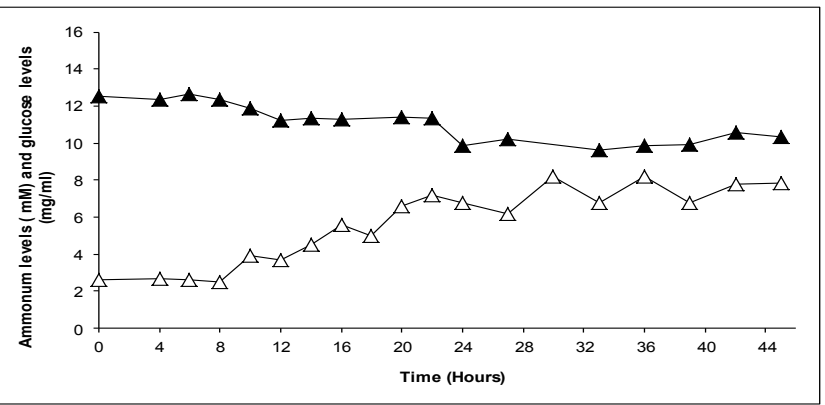

Fig. 1C- Fermentation profile of Streptomyces coelicolor growing in modified YEME media Ammonium production, $\mathrm{mM}(\triangle)$ and glucose utilisation, $\mathrm{mg} / \mathrm{ml}$.

\section{Conclusions}

Growth of $S$. coelicolor in this medium showed a biphasic growth pattern; the second phase of which was associated with the syn- thesis of red pigment. Measured nutrient levels indicated that phosphorus from the medium was consumed initially at a high rate. As phosphorus levels declined, alkaline phosphatase activity rose. As the enzyme levels became elevated the levels of phosphorus in the medium transiently increased, suggesting that phosphorus was re-released from the biomass from some unidentified source, possibly teichoic acids. The appearance of the red pigment (prodigiosin-like) seemed to be regulated by phosphate repression, a phenomenon previously well established for this organism. The lack of production of the blue pigment actinorhodin was thought to be due to the release of ammonium ions, resulting from the use of amino compounds as carbon sources for growth. This study illustrates the need to take a holistic approach to the organism's metabolism when investigations are conducted in complex media. Nutrients, such as phosphates, sugars and amino compounds, are interrelated with one another and secondary metabolic processes.

\section{References}

[1] Bekesy I., Szabo G. and Valu G. (1966) Arch Microbiol 54, 125-128.

[2] Bentley S.D., Chater K.F., Cerdeno-Tarraga A.M., Challis G.L., Thomson N.R., James K.D., Harris D.E., Quail M.A., Kieser H., Harper D., Bateman A., Brown S., Chandra G., Chen C.W., Colllins M., Cronin A., Fraser A., Goble A., Hilalgo J., Hornsby T., Howarth S., Huang C.H., Kieser T., Larke L., Murphy L., Oliver K., O'Neil S., Robbinowitsch E., Rajandream M.A., Rutherford B.G., Rutter S., Seeger K., Saunders D., Sharp S., Squares S., Taylor K., Warren T., Wietzorrek A., Woodward J., Barrell B.G., Parkhill J. and Hopwood D.A. (2002) Nature, 417, 141-147.

[3] Bhavsar A.P., Erdman L.K., Schertzer J.W. and Brown E.D. (2004) J Bact 186, 7865-7873.

[4] Cashel M., Gentry D.R., Hernandez V.G. and Vinella D. (1996) The stringent response, In Neidhardt F.C., Curtiss R., Ingraham J.L., Lin E.C.C., Low K.B., Magasanik B., Reznikoff W.S., Riley M., Schaechter M. \& Umbarger H.E. (ed.), Escherichia coli and Salmonella: cellular and molecular biology., 1458-1496.

[5] Doull J.L. and Vining L.C. (1990) Appl Microbiol Biotech 32 449-454.

[6] Grant W.D. (1979) J. Bact, 137, 35-43.

[7] Hobbs G., Frazer C.M., Gardner D.C.J., Cullum J.A. and Oliver S.G. (1989) Appl. Microbiol. Biotechnol., 31, 272-277.

[8] Hobbs G., Frazer C.M., Gardner C.J., Flett F. and Oliver S.G. (1990) J. Gen Microbiol. 136, 2291-2296.

[9] Hobbs G.A., Obanye I.C., Petty J., Mason J.C., Barrat E., Gardner D.C.J., Flett F., Smith C.P., Broda P. and Oliver S.G. (1992) J. Bact, 174, 1487-1494.

[10]Hodgson D.A. (2000) Adv. Micro. Phys.,42, 49-208.

[11]Hopwood D.A. (1999) Microbiol., 145, 2183-2202.

[12]Hoskisson P.A, Sharples G.P. and Hobbs G. (2003) Letts Appl Microbiol 36, 268-271.

[13]Hunter I.S. and Hill R.A. (1997) Biotechnology of Industrial Antibiotics.

[14]Kieser T., Bibb M., Buttner M.J., Chater K.F. and Hopwood D.A. (2000) Practical Streptomyces genetics. The John Innes Foundation. 
[15]McDowall K., Thamchaipenet A. and Hunter I.S. (1999) J. Bact., 181, 3025-3032.

[16]Martin J.F. (2004) J. Bact., 186, 5197-5201.

[17]Moura R.S., Martin J.F., Martin A. and Liras P. (2001) Microbiol., 147, 1525-1533.

[18]Plummer D.T. (1987) An Introduction to Practical Biochemistry. 3rd Edition McGraw-Hill London.

[19]Pooley H.M. and Karamata D. (1994) Teichoic acid synthesis in Bacillus subtilis: genetic organization and biological roles. In Ghuysen J.M. \& Hakenbeck R. (eds). Bacterial Cell Wall., 187 $-198$.

[20]Sola-Landa A., Moura R.S. and Martin J.F. (2003) TPNAS USA 100, 6133-6138.

[21]Sola-Landa A., Rodriguez-Garcia A., Franco-Dominguez E. and Martin J.F. (2005) Mol Microbiol., 56, 1373-1385. 